\title{
PARTISIPATORY DIRECTING IN THE FILM NOISE IN SILENCE
}

\author{
Reskyana Syam ${ }^{1}$, Titus Soepono Adji ${ }^{2}$, dan Abas Fauzi ${ }^{3}$ \\ ${ }^{1}$ Institut Seni dan Budaya Indonesia Sulawesi Selatan, Indonesia \\ ${ }^{2}$ Institut Seni Indonesia (ISI) Surakarta, Indonesia \\ ${ }^{3}$ Institut Seni dan Budaya Indonesia Sulawesi Selatan, Indonesia \\ E-mail: reskyana29@gmail.com
}

\begin{abstract}
Deaf people are social groups that are protected by the Law of the Republic of Indonesia Number 8 of 2016 concerning Persons with Disabilities, but they still feel injustice or unfair in the world of education and in society environment. The above problems are the basis for the creation of the documentary film Noise In Silence. The type of research used is artistic research which produces a documentary film work. Documentary film production is carried out using a participatory directing style, while the analysis uses a visual approach. The resulting documentary film shows the participatory style can support the discovery of answers to the director's doubts, and can reveal the subject's experience in depth so that it can be captured by the audience. In addition, the dramatization of the presentation was successfully realized, so that this film has a high influence on the emotional level of the audience.
\end{abstract}

Keywords: Deaf, documentery film, and partisipatory style

\begin{abstract}
ABSTRAK
Penyandang tuli merupakan kelompok sosial yang sudah dilindungi oleh Undang-Undang Republik Indonesia Nomor 8 Tahun 2016 Tentang Penyandang Disabilitas, namun mereka masih merasakan ketidakadilan di dalam dunia pendidikan dan di tengah masyarakat. Permasalahan di atas menjadi dasar penciptaan film dokumenter Noise In Silence. Jenis penelitian yang digunakan adalah penelitian artistik yang menghasilkan sebuah karya film dokumenter. Produksi film dokumenter dilakukan dengan menggunakan gaya penyutradaraan partisipatori, sedangkan analisisnya memakai pendekatan visual. Film dokumenter yang dihasilkan menunjukkan gaya partisipatori dapat mendukung penemuan jawaban dari keraguan-keraguan sutradara, dan dapat mengungkap pengalaman subjek secara mendalam sehingga bisa ditangkap oleh penonton. Selain itu, dramatisasi dalam pembabakan berhasil diwujudkan, agar film ini mempunyai daya pengaruh yang tinggi terhadap tingkat emosional penonton
\end{abstract}

Kata kunci: Penyandang tuli, film dokumeter, dan gaya partisipatori

\section{PENDAHULUAN}

Sejak tahun 2016 hingga sekarang, tunarungu atau tuli menjadi isu hangat atas keberadaannya di Indonesia khususnya di sekitar Makassar. Banyaknya masyarakat yang masih melakukan diskriminasi dengan mengucilkan penyandang tuli ketika berada di tengah masyarakat. Penyiksaan secara fisik ataupun mental dilakukan oleh masyarakat tanpa memandang usia baik remaja maupun dewasa. Masyarakat masih banyak yang beranggapan bahwa tuli hanya mampu sekolah di sekolah luar biasa (SLB), berinteraksi dengan sesamanya, dan hanya mampu bekerja menggunakan fisik saja seperti tukang parkir, pegawai warung kopi, 


\section{CAPTURE}

dan buruh angkut. Jika ada penyandang tuli yang bekerja sebagai pegawai kantor, hal itu dikarenakan hasil kolusi karena memiliki famili seorang pejabat.

Penyandang disabilitas memiliki peluang $2 \%$ kesempatan kerja di ranah pegawai negeri sipil dan 1\% swasta. Hasil riset Netherlands Leprosy Relief (NLR) menunjukkan bahwa 54\% responden yang lulus mengikuti sekolah formal, orang dengan gangguan mobilitas adalah yang paling sedikit dan orang dengan gangguan pendengaran adalah yang terbanyak berpartisipasi dalam sekolah sekolah formal. Meskipun penyandang tuli telah banyak yang menikmati pendidikan, namun mereka belum bisa merasakan pendidikan yang sama dengan orang-orang pada umumnya. Undang-Undang Republik Indonesia Nomor 8 Tahun 2016 Tentang Penyandang Disabilitas telah mengatur hak pendidikan disabilitas pada bagian keenam pasal 10 ayat (a) berbunyi: mendapatkan pendidikan yang bermutu pada satuan pendidikan di semua jenis, jalur, dan jenjang pendidikan secara inklusi dan khusus. Meskipun regulasi sudah ditentukan, namun masih banyak penyandang tuli yang mengalami ketidakadilan, sehingga kesetaraan yang telah ditentukan di dalam undang-undang masih sebatas imajinasi semata bagi penyandang tuli.

Di tengah kondisi yang kurang menggembirakan tersebut, para penyandang tuli melakukan kegiatan "pergerakan" yang bisa menunjukkan kepada masyarakat bahwa penyandang tuli itu ada. Salah satu kegiatannya yakni Seminar Bahasa Isyarat yang dihadiri oleh penyandang tuli dan non penyandang tuli yang menghadirkan pemateri tuli, sehingga seminar tersebut menggunakan bahasa isyarat. Hal ini memberi inspirasi bahwa ada cara komunikasi yang berbeda untuk menyampaikan aspirasi dalam suatu forum ilmiah.

Bambang Ramadan, seorang penyandang tuli yang memiliki saudara kembar yang normal, mempunyai semangat melakukan perubahan terhadap tindakan diskriminasi, sejak ia menempuh pendidikan SMA (SLB) hingga perguruan tinggi. Kemampuan Bambang selalu dikembangkan hingga menguasai beberapa bahasa isyarat yaitu Bahasa Isyarat Indonesia (Bisindo) Makassar, Sistem Bahasa Isyarat (SIBI), Bisindo Bali, Bisindo Jakarta dan Inggris. Bambang menempuh kuliah di Politeknik Pariwisata Makassar dan merupakan mahasiswa tuli pertama.

Istilah tuli (deaf) atau kurang dengar (hard of hearing) lebih popular di kalangan tunarungu. Para penyandang tunarungu lebih senang disebut tuli atau hard of hearing (h.o.h) sesuai dengan kondisi mereka dibanding disebut tunarungu. Tunarungu adalah seseorang yang mengalami gangguan pada organ pendengarannya sehingga mengakibatkan 
ketidakmampuan mendengar, mulai dari tingkat yang ringan hingga yang berat sekali, yang diklasifikasikan ke dalam tuli (deaf) dan kurang dengar (hard of hearing). Gangguan pada organ pendengaran biasa terjadi pada telinga luar, tengah, maupun bagian dalam (Hernawati, 2007).

Istilah yang populer di lapisan masyarakat adalah tunarungu. Istilah tuli menjadi pilihan kata yang akan digunakan. Ketidaktahuan masyarakat tentang keberadaan tuli dan eksistensi tuli yang sebenarnya adalah sebuah tantangan agar kesejahteraan penyandang disabilitas yang dicanangkan Undang-Undang Republik Indonesia Nomor 8 Tahun 2016 dapat bisa terwujud.

"Pergerakan" para penyandang tuli di atas perlu didukung agar keberadaannya mendapat perhatian dari masyarakat, salah satunya melalui film dokumenter. Film dokumenter ini merupakan video advokasi dan aspirasi yang diwakili oleh beberapa tokoh tuli yang telah mengalami sikap diskriminasi. Film dokumenter yang diproduksi ini berjudul Noise in Silence. Judul ini berarti keramaian dalam keheningan mewakili keadaan subjek baik segi keberadaan maupun komunikasi.

Film ini menggunakan gaya partisipatori agar penonton dapat menangkap kegiatan, percakapan, dan interaksi tokoh dan sutradara. Hadirnya sutradara dalam frame agar memudahkan penonton memperoleh informasi disebabkan subjeknya menggunakan bahasa isyarat. Partisipasi antara sutradara dan subjek merupakan keterlibatan langsung selama proses pembuatan film.

\section{TINJAUAN PUSTAKA}

Tinjauan dalam pembuatan film dokumenter menggunakan sumber referensi audiovisual yakni film dokumenter yang memiliki kesamaan konsep ataupun tema. Film dokumenter yang ditinjau yakni Planet of Snail, Happy, dan Indonesia Debt Cult.

\section{a. Film Planet of Snail}

Planet of Snail merupakan film dokumenter yang berasal dari Korea Selatan. Film ini telah dirilis pada tanggal 22 Maret 2012. Film berdurasi 70 menit dan disutradarai oleh Yi Seung Jun ini bercerita tentang seorang penyair tuli dan buta yang bernama Young Chan.

Film Planet of Snail menggunakan struktur dramatik dalam penuturan ceritanya. Cerita diawali dengan pengenalan tokoh (Young Chan) melalui adegan bermain layang-layang lalu menyebut namanya, memperbaiki bola lampu di langit-langit kamar, mempelajari tekstur alam, menulis naskah hingga naskahnya dipentaskan oleh temantemannya. Struktur dramatik film Planet Of Snail sesuai dengan penjelasan RB Armantono Paramita bahwa struktur dramatik yang baik menempatkan peristiwaperistiwa pada posisi yang tepat untuk membangkitkan keterlibatan emosional 
yang maksimal dari penonton (Paramita, 2017). Struktur dramatik pada film Planet of Snail menjadi referensi struktur dramatik bagi pembuatan film Noise In Silence yang menempatkan peristiwa-peristiwa dalam film untuk meningkatkan emosional penonton.

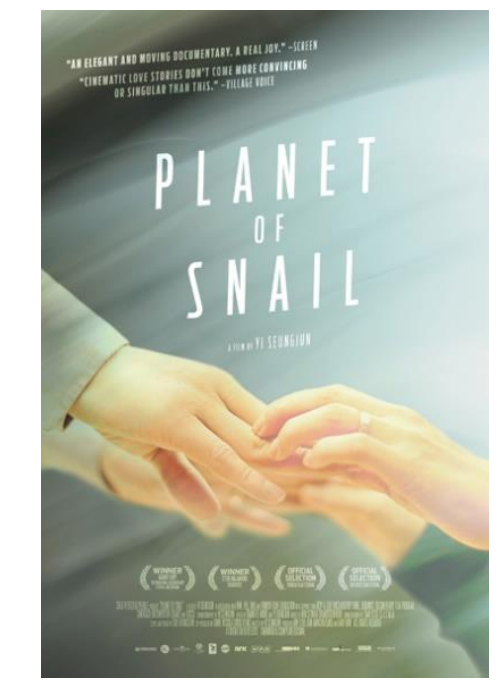

Gambar 1. Poster film Planet of Snail (Sumber: https://www.imdb.comtitlett2057455 mediaviewerrm3126511872)

Kesamaan film Noise in Silnece dengan film tersebut adalah tema. Keduanya bertemakan sosial tentang penyandang disabilitas, adapun perbedaan keduanya terletak pada subjek utama. Film Planet of Snail mengangkat kisah hidup Young Chan, penyandang disabilitas tuna netra dan tuna rungu (penyandang tuli) bersama istrinya (Soon-Ho) yang menjadi penyandang disabilitas fisik (daksa) dengan ukuran badan di bawah normal. Film Noise in Silence mengangkat kisah penyandang tuli yang bernama Bambang Ramadan sebagai subjek utama yang telah mengalami tuli sejak ia masih kecil. b. Film Happy

Film Happy berdurasi 85 menit, dirilis pada tahun 2016 dan disutradarai oleh Carolin Genreith. Sutradara berperan serta di dalam film ini. Peran sutradara sebagai anak dari Dieter. Ini memberi ruang bagi sutradara untuk memaksimalkan partisipasi dalam menyampaikan gagasannya atas keraguannya. Film Happy menjadi sumber referensi bagi pembuatan film Noise in Silence khususnya aspek penyutradaraan. Fokusnya pada gagasan atas keraguan dan pemahaman sutradara tetap berada dalam film yang diproduksi.

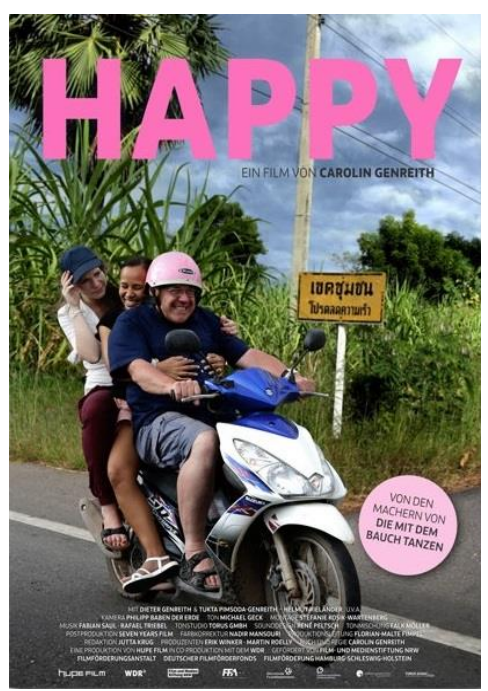

Gambar 1. Poster film Happy

(Sumber : https://www.imdb.com/title/tt6646916/ mediaviewer/rm13642137600

Film dokumenter Happy memiliki perbedaan dengan film Noise In Silence ini yakni pada tema. Film Happy bertemakan lansia, sedangkan film Noise In Silence mengangkat tema penyandang disabilitas tunarungu atau tuli. Meskipun begitu, keduanya memiliki persamaan yakni samasama menggunakan gaya penyutradaraan 
partisipatori.

\section{c. Film Kutukan Tanah Ngarai}

Film Kutukan Tanah Ngarai dengan durasi 28 menit 24 detik disutradarai oleh Muh. Nur Falah Muzakkir. Film ini bercerita tentang Komunitas To Balo yang mengalami diskriminasi di masyarakat setempat. Film dokumenter ini menggunakan gaya dokumenter partisipatori dalam penyutradaraannya. Sutradara terlibat langsung di dalam film dalam bentuk suara. Film ini menjadi sumber referensi bagi penciptaan film Noise in Silence khususnya bagian penyutradaraan yakni keterlibatan sutradara pada film baik dalam frame maupun di luar frame.

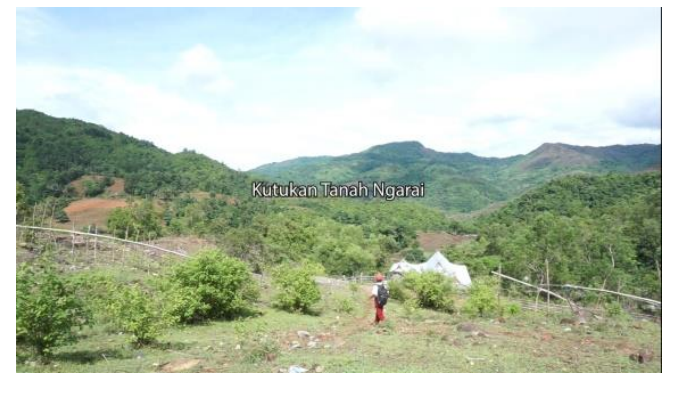

Gambar 2. Screenshot film

(Sumber: Kutukan di Tanah Ngarai, Februari 2019)

Film dokumenter Noise in Silnece memiliki kesamaan tema dengan film Kutukan Tanah Ngarai yakni permasalahan kehidupan masyarakat, sedangkan perbedaannya terletah pada subjek. Film Kutukan Tanah Ngarai mengangkat kehidupan Komunitas Tu Balo yang dikucilkan oleh masyarakat dan subjek bukan penyandang disabilitas. Adapun film Noise in Silence mengangkat kisah perjuangan Bambang Ramadan, seorang penyandang tuli yang berjuang dan mendapat dukungan dari keluarganya.

Selain melakukan tinjauan pustaka audio visual, penulis juga meninjau beberapa buku referensi, dan dihasilkan kerangka teori sebagai landasan dalam penciptaan karya ini, sebagai berikut.

a. Tuli

Kamus Besar Bahasa Indonesia mendefinisikan tuli itu tidak dapat mendengar (karena rusak pendengarannya); pekak;. Penyandang tunarungu atau sering disebut penyandang tuli merupakan sesorang yang mengalami keterbatasan dalam tingkat pendengaran (KBBI, 2016). Definisi itu sejalan dengan pendapat Setyo Wahyu Wibowo yaitu "ketulian" adalah sama dengan "kurang pendengaran" (Wibowo, n.d.).

Penyebab keterbatasan pendengarannya beragam setiap individunya. Ada penyandang tuli sejak ia lahir, ada juga dikarenakan demam tinggi, dan jumlah yang lebih tinggi yakni disebabkan oleh kecelakaan seperti jatuh di ayunan saat kecil, jatuh saat bermain ataupun kecelakaan kendaraan. Penyandang tuli yang mengalami ketulian sejak lahir memiliki potensi keterlambatan dalam pemahaman. Tingkat emosionalnya lebih tinggi karena kurangnya pemahaman atau pengetahuan yang diperoleh. Berbeda lagi dengan penyandang tuli yang disebabkan karena kecelakaan saat berusia 4-7 tahun, biasanya usia seperti itu telah 


\section{CAPTURE}

merekam berbagai macam kosa kata sehingga mempengaruhi sikap dan respon yang akan dikeluarkan ketika menghadapi suatu permasalahan.

\section{b. Film Dokumenter}

Bill Nichols berpendapat bahwa setiap film adalah dokumenter, tetapi terbagi dengan dua kategori yakni dokumenter pemenuhan keinginan biasa atau disebut dengan fiksi, dan dokumenter representasi kehidupan sosial atau sering disebut dengan non fiksi (Nichols, 2001).

Fajar Nugroho mengatakan bahwa film dokumenter adalah sebuah film yang mendokumentasikan kenyataan yang sesuai dengan fakta (Nugroho, 2001). Lebih jauh, John Gierson (Tanzil, 2010) (Fahriansyah et al., 2018) mengatakan pembuat dokumenter haruslah menempatkan diri sebagai seorang propagandis, yang mengangkat tema-tema dramatis dari kehidupan di sekelilingnya sebagai suatu kewajiban sosial atau kontribusi terhadap lingkungan dan budaya. Tema penyandang tuli termasuk dalam tema-tema dramatis kehidupan di sekitar kita.

\section{c. Penyutradaraan Partisipatori}

Banyak film dokumenter yang telah dihasilkan sineas fiksi seperti Renita-Renita karya Tony Trimarsanto, The Unseen Words karya Wahyu Utami, Wayang Sampah Laut karya Sito Fossy Biosa, dan sebagainya. Setiap pembuat film dokumenter memiliki gaya penyutradaan masing-masing. Salah satu gaya yang biasa digunakan yakni penyutradaraan gaya partisipatori yang menekankan interaksi antara pembuat film dan subjeknya dengan memposisikan sutradara sebagai partisipan bukan sebagai observator dan ditampilkan dalam film (Ratmanto, 2018).

Sutradara juga dapat menampilkan jawaban atas keraguan-keraguan yang dirasakan dengan menggunakan penyutradaaran gaya partisipatori. Hal ini sesuai dengan pendapat Rabiger Michael yang mengatakan bahwa dalam pembuatan film partisipatori, sutradara bisa berbagi keraguan yang ditemukan dan aspek dalam proses pembuatan film untuk penonton (Rabiger, 2014).

\section{METODE}

Pendekatan yang digunakan penciptaan film dokumenter ini adalah Penelitian Artistik, yaitu penelitian melalui kerja kreatif dalam seni (Guntur \& Sugihartono, 2015). Kerja kreatif dalam hal ini adalah penciptaan film dokumenter dengan tahapan yang terstruktur dan sistematis. Tahapan produksi karya audio visual baik film maupun program televisi meliputi praproduksi, produksi, dan pascaproduksi. Produksi film dokumenter, tahap produksinya lebih banyak menyita waktu untuk riset (Ayawaila, 2008).

Riset dilakukan melalui observasi dan interview. Objek material khususnya penyandang tuli dilakukan diobservasi langsung sehingga memperoleh informasi 
yang diinginkan, serta dilakukan wawancara untuk menggali informasi yang lebih dalam. Objek formal dilakukan proses riset dengan fokus pada jurnal dan buku-buku yang berkaitan dengan film dokumenter, gaya penyutradaraan, dan tangga dramatik.

Pentingnya kreativitas pembuat dalam menyusun alur pada konflik-konflik agar menjadi menarik dengan memperhatikan aspek dramatiknya. Struktur dramatik yang baik menempatkan peristiwa-peristiwa pada posisi yang tepat untuk membangkitkan keterlibatan emosional yang maksimal dari penonton (Paramita, 2017). Salah satu struktur lazim yakni struktur tiga babak, yakni babak persiapan, babak konfrontasi, dan babak resolusi (Pratista, 2008).

Hasil kreasi dalam penelitian artistik ini berbentuk karya seni yaitu film dokumenter. Hasil kreasi tersebut dianalisis dan dideskripsikan dengan pendekatan visual menjadi sebuah paparan yang menggambarkan penyutradaan partisipatori dilakukan dan dramatisasinya mulai babak 1 sampai babak 3 .

\section{PEMBAHASAN}

Film dokumenter Noise In Silence ini mengisahkan usaha penyandang tuli, Bambang Ramadan, dalam memperoleh pendidikan. Spesifikasi film ini sebagai berikut.
1) Judul Karya : Noise In Silence
2) Format: Film Dokumenter Partisipatori
3) Durasi: 22 menit

4) Tema karya: Perjuangan mendapatkan pendidikan yang layak

5) Sasaran khalayak: Semua umur

6) Karakteristik: Single camera dan multi camera

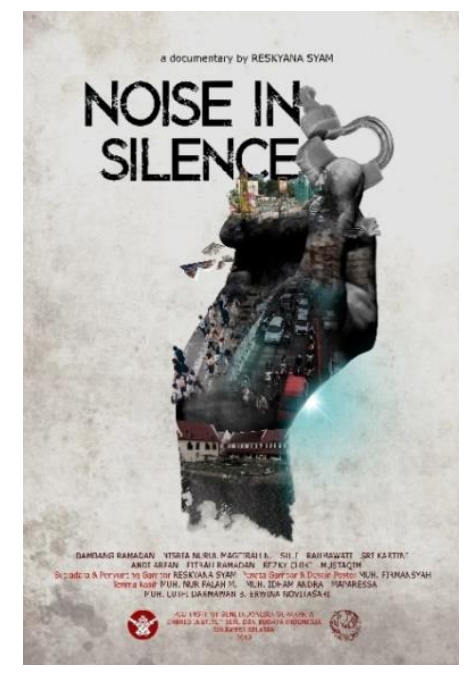

Gambar 4. Poster film Noise In Silence (Desain: Manca Design, 2019)

\subsection{Penyutradaraan Partisipatori}

Film Noise In Silence memperlihatkan sutradara hadir di dalam frame untuk menemukan jawaban dari keraguan-keraguan kepada subjek utama ataupun subjek pendukung sehingga dapat ditangkap oleh penonton. Hal ini sejalan dengan teori Rabiger Michael (2014) tentang film partisipatori, sutradara bisa berbagi keraguan yang ditemukan dan aspek dalam proses pembuatan film untuk penonton. Kehadiran sutradara dalam scene pertama yakni saat wawancara yang menunjukkan bahwa informasi yang telah diperoleh dari subjek utama (Bambang Ramadan) diklarifikasi langsung dengan ibu kandung Bambang. 


\section{CAPTURE}

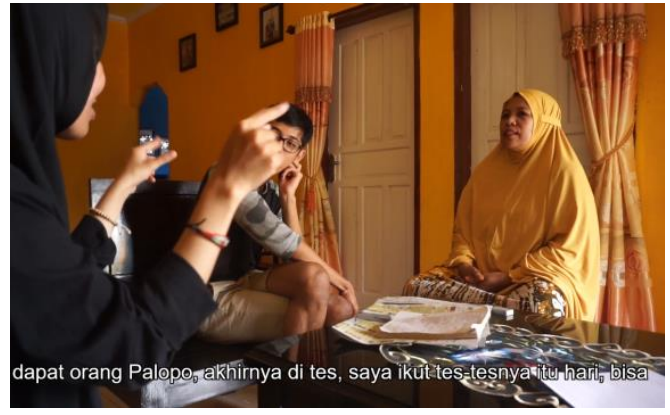

Gambar 5. Wawancara dengan ibu kandung Bambang

(Sumber: Noise In Silence, TC : 00:01:05

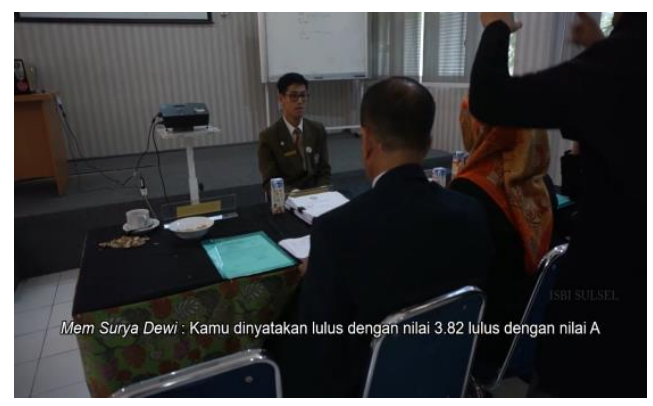

Gambar 6. Saat Ujian Berlangsung

(Sumber: Noise In Silence, TC : 00:20:39)

Kehadiran sutradara dalam film Noise In Silence ini sebagai juru bahasa isyarat dari subjek utama (Bambang Ramadan), sekaligus pendamping subjek. Hal ini tampak pada scene pendaftaran ujian dan saat ujian. Pendekatan ini sesuai dengan pendapat Aan Ratmanto menyebutkan gaya partisipatori menekankan interaksi antara pembuat film dan subjeknya (Ratmanto, 2018).

Scene yang memperlihatkan upaya menjawab keraguan juga tampak pada adegan wawancara kepada beberapa subjek pendukung yakni Anggi, Suli, Ramhawati, Fitrah, dan Aqim ketika pelatihan sablon. Keraguan sutradara fokus pada bagaimana pembelajaran penyandang tuli di sekolah luar biasa (SLB) masing- masing dan apakah pembelajaran itu layak diterima oleh penyandang tuli.

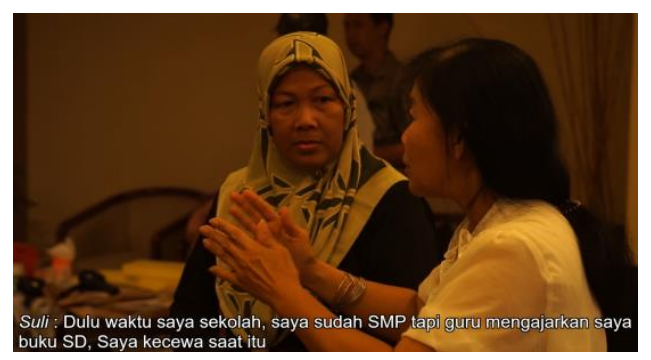

Gambar 7. Wawancara kepada subjek pendukung (Sumber: Noise In Silence, TC : 00:10:26)

\subsection{Tangga Dramatisasi}

Film dokumenter Noise In Silence menerapkan tangga dramatik atau struktur dramatik untuk memudahkan penonton memahami film. Struktur dramatik yang digunakan yakni struktur tiga babak. Struktur dramatik mempunyai pengaruh yang tinggi terhadap tingkat emosional penonton atau reaksi penonton. Sutradara menempatkan scene-scene yang meningkatkan emosional penonton. Berikut pembahasan dramatik berdasarkan pembagian babak.

Tabel 1. Susunan scene babak 1

\begin{tabular}{|c|c|c|}
\hline No. & Scene & Timecode \\
\hline 1 & $\begin{array}{l}\text { Cerita orang tua } \\
\text { Bambang mengenai } \\
\text { perjuangan Bambang }\end{array}$ & $\begin{array}{l}00.00 .24 \\
- \\
00.02 .54\end{array}$ \\
\hline 2 & $\begin{array}{l}\text { Deskripsi Kota } \\
\text { Makassar TC }\end{array}$ & $\begin{array}{l}00.02 .55- \\
00.03 .19\end{array}$ \\
\hline 3 & $\begin{array}{l}\text { Tuli, cara komunikasi, } \\
\text { dan pembahasan tuli }\end{array}$ & $\begin{array}{l}00.03 .20- \\
00.03 .55\end{array}$ \\
\hline 4 & Populasi tuli & $\begin{array}{l}00.03 .56- \\
00.44 .47\end{array}$ \\
\hline 5 & $\begin{array}{l}\text { Sudut pandang } \\
\text { masyarakat terhadap } \\
\text { penyandang tuli }\end{array}$ & $\begin{array}{l}00.04 .47- \\
00.05 .28\end{array}$ \\
\hline
\end{tabular}

Babak I adalah babak persiapan 
untuk memunculkan perhatian penonton atau emosi penonton. Babak ini menggambarkan perjalanan Bambang Ramadan yang diawali dengan munculnya sosok ibu yang menjelaskan kisah awal Bambang menempuh kuliah. Cerita ibunya tersebut mengajak penonton untuk menyimak hal-hal yang telah dilakukan Bambang dan perlakukan yang telah diterimanya selama menempuh kuliah. Cerita yang dituturkan ibu kandung menjadi kunci penarik penonton di menit pertama.

Babak ini menampilkan juga establish Kota Makassar yang menunjukkan lokasi perantauan Bambang selama menimba ilmu di perguruan tinggi yaitu Politeknik Pariwisata Makassar. Scenescene selanjutnya menampilkan cara komunikasi, populasi, dan perlakuan orangorang terhadap penyandang tuli.

Penempatan establish Kota Makassar setelah wawancara bersama ibu kandung Bambang, mampu menetralkan kembali emosi penonton sehingga penonton lebih rileks dari scene sebelumnya. Scene selanjutnya kembali mengangkat emosi penonton pada level tengah, dengan menampilkan sudut pandang masyarakat yang memandang penyandang tuli sebagai bahan tontonan. Scene ini dimaksudkan untuk menyampaikan kepada penonton tentang kondisi yang dihadapi penyandang tuli baik di masyarakat ataupun di lingkup pendidikan. Urutan scene seperti tampak pada tabel 1 di atas selaras dengan pendapat RB Armantono Paramita bahwa peristiwa-peristiwa ditempatkan pada posisi yang tepat (Paramita, 2017).

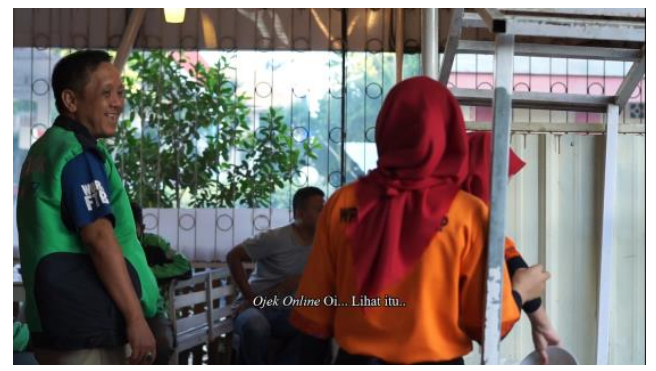

Gambar 8. Sudut pandang masyarakat (Sumber: Noise In Silence, TC: 00:04:21)

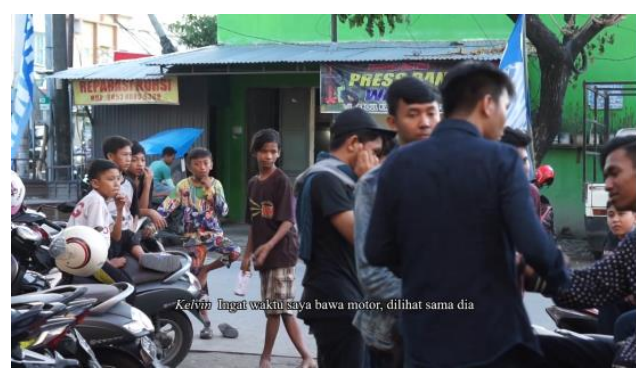

Gambar 9. Penyandang tuli sedang ngobrol (Sumber: Noise In Silence, TC:00:04:36)

Tabel 2. Susunan scene babak 2

\begin{tabular}{|c|l|c|}
\hline No & \multicolumn{1}{|c|}{ Scene } & Timecode \\
\hline 1. & $\begin{array}{l}\text { Bambang memberi } \\
\text { keterangan tentang } \\
\text { sekolah luar biasa (SLB), } \\
\text { kondisi pendidikan tuli, } \\
\text { dan bimbingan }\end{array}$ & $\begin{array}{l}00.05 .30 \\
00.08 .12\end{array}$ \\
\hline 2. & $\begin{array}{l}\text { Menceritakan hambatan } \\
\text { di kampus saat } \\
\text { bimbingan }\end{array}$ & $\begin{array}{c}00.08 .15- \\
00.08 .54\end{array}$ \\
\hline 3. & $\begin{array}{l}\text { Melakukan bimbingan di } \\
\text { kampus }\end{array}$ & $00.08 .55-$ \\
00.10 .28 \\
\hline 4. & $\begin{array}{l}\text { Penjelasan berdasarkan } \\
\text { pengalaman tentang cara } \\
\text { belajar di SLB, kampus } \\
\text { dan solusi yang } \\
\text { diinginkan penyandang } \\
\text { tuli yang dijelaskan oleh } \\
\text { subjek pendukung yakni } \\
\text { Anggi, Suli, Rahmawati, } \\
\text { dan Fitrah }\end{array}$ & $00.10 .30-$ \\
\hline
\end{tabular}

Babak II memperlihatkan permasalahan melalui scene wawancara 
Bambang dengan sutradara tentang gambaran umum kondisi sekolah luar biasa (SLB) dan setelah lulus di SLB. Menurut Himawan Pratista, di babak II biasanya muncul kejutan yang lebih kompleks (Pratista, 2008). Kejutan terletak pada babak kedua film ini khususnya scene penjelasan subjek tentang SLB dan berbagai macam tindak diskriminasi yang diperolehnya.

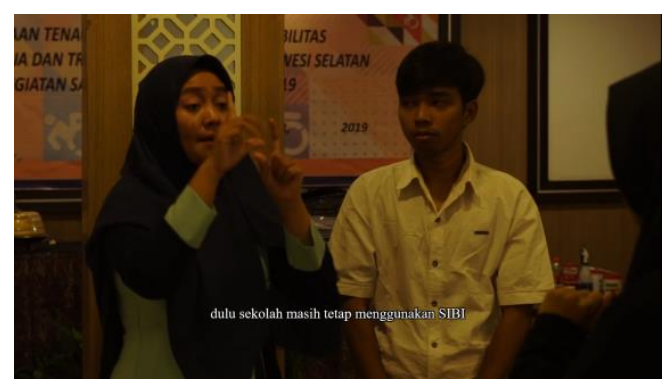

Gambar 10. Anggi menjelaskan SIBI dan BISINDO

(Sumber: Noise In Silence TC: 00:12:17)

Penempatan scene-scene di babak

II masih mempertimbangkan emosional penonton. Urutan scene pada tabel 2 memiliki tingkat emosional yang berbeda. Scene nomor 1 masih berada di level tengah, dan puncak emosional penonton berada di nomor 4, sebagaimana cuplikan layar tampak pada gambar 10. Poin yang menentukan emosional penonton adalah ketika mengetahui bahwa penyandang tuli telah mengalami diskriminasi di sekolah hingga perguruan tinggi. Selain itu, polemik bahasa yang digunakan oleh beberapa penyandang tuli. Hal itu dapat membuat penonton semakin penasaran dan emosional.

Tabel 3. Susunan scene babak 3

\begin{tabular}{|c|l|l|}
\hline No & \multicolumn{1}{|c|}{ Scene } & \multicolumn{1}{|c|}{ Timecode } \\
\hline 1. & $\begin{array}{l}\text { Harapan Bambang untuk } \\
\text { penyandang tuli dan non } \\
\text { penyandang tuli }\end{array}$ & $\begin{array}{l}00.16 .37- \\
00.18 .17\end{array}$ \\
\hline 2. & Daftar Ujian & $00.18 .20-$ \\
& & 00.19 .20 \\
\hline 3 & Ujian Sidang & $00.19 .21-$ \\
& & 00.21 .51 \\
\hline
\end{tabular}

Babak III merupakan babak penutupan atau klimaks dari film Noise In Silence. Babak ini mempelihatkan Bambang menyampaikan harapan, melakukan pendaftaran ujian, dan melakukan ujian sidang.

Babak III scene nomor 1 pada tabel 3 di atas merupakan scene yang menurunkan emosional penonton, namun scene mendaftar ujian mengantarkan penonton pada level tengah tingkat emosional. Scene saat ujian mengantarkan penonton pada level emosional yang tinggi, karena melahirkan keharuan dengan nilai yang dicapai Bambang serta tangisan yang dihadirkan bersama dengan pelukan dari seorang dosen pembimbing.

Setelah scene ujian, muncul judul Noise In Silence, dan dilanjut munculnya credit title menjadi puncak emosional penonton, karena penonton masih larut dengan keterharuan yang dirasakan di akhir film ini. 


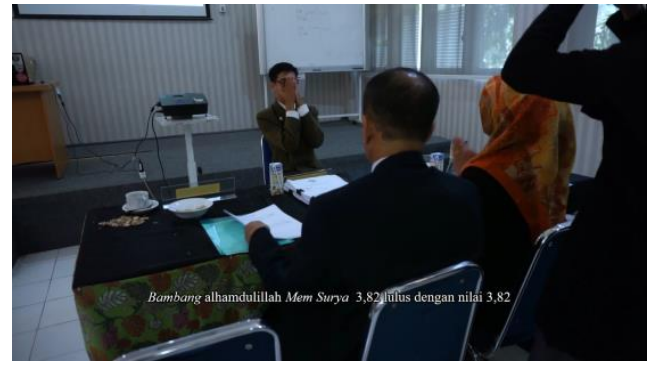

Gambar 11. Bambang menghadapi ujian sidang (Sumber: Noise In Silence TC 00:20:44)

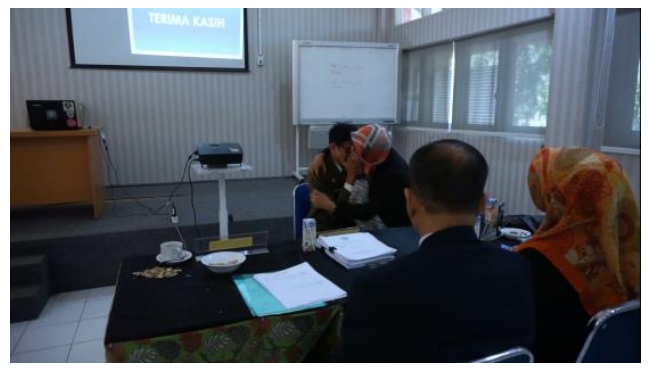

Gambar 12. Suasana haru (Sumber: Noise In Silence TC 00:21:05)

\section{SIMPULAN}

Film dokumenter berjudul Noise In Silence menitikberatkan

pada permasalahan dan hambatan yang dialami oleh penyandang tuli selama menempuh pendidikan. Proses penggarapan film dokumenter ini menggunakan gaya partisipatori agar mampu menarik perhatian penonton.

Penyutradaraan gaya partisipatori diwujudkan dengan hadirnya sutradara dalam frame sebagai juru bahasa isyarat. Hadirnya juga sutradara tampak ketika mewawancarai langsung subjek utama (Bambang Ramadhan) dan subjek pendukung untuk mengemukakan keraguraguan yang telah ditemukan selama riset ke dalam film Noise In Silence.

Penerapan gaya partisipatori yang disajikan dalam tiga babak mampu menggambarkan bagaimana perjuangan penyandang tuli dalam menyetarakan dirinya. Selain itu, film ini bisa menjadi media pendukung advokasi di bidang pendidikan khusus penyandang tuli agar penyandang tuli bisa merasakan kesetaraan.

\section{DAFTAR ACUAN}

Ayawaila, G. R. (2008). Dokumenter: Dari Ide Sampai Produksi. IKJ Press.

Fahriansyah, E., Sasongko, H., \& Krishna, A. (2018). Gadang House in Documentary Film of the Adat Nagari Sijunjung District. CAPTURE: Jurnal Seni Media Rekam, 10(1), 88-100. https://doi.org/10.33153/capture.v1 0i1.2244. 88-100

Guntur, \& Sugihartono, R. A. (2015). Metodologi Penelitian Artistik. ISI Press \& P3AI ISI Surakarta.

Hernawati, T. (2007). Pengembangan Kemampuan Berbahasa dan Berbicara Anak Ts, Biilsunarungu. Jassi_Anakku, 7(1).

KBBI. (2016). Kamus Besar Bahasa Indonesia. Kemendikbud RI. https://kbbi.kemdikbud.go.id/

Nichols, B. (2001). Introduction to Documentary. Indiana University Press.

Nugroho, F. (2001). Cara Pintar Bikin Film. Penerbit Indonesia Cerdas.

Paramita, R. A. (2017). Skenario Film. Pusbang Perfilman Kementrian Pendidikan dan Kebudayaan.

Pratista, H. (2008). Memahami Film. Homerian Pustaka.

Rabiger, M. (2014). Directing the 


\section{CAPTURE}

Documentary. CRC Press.

Ratmanto, A. (2018). Film Dokumenter Sejarah sebagai Alternatif Historiografi di Indonesia. SASDAYA : Journal of Humanities, 2(2), 404-414.

Tanzil, C. (2010). Pemula dalam Film Dokumenter: Gampang-Gampang Susah. In-Docs.

Wibowo, S. W. (n.d.). Ketulian: Pemeriksaan dan Penyebabnya. Retrieved June 8, 2020, from http://file.upi.edu/Direktori/FIP/JUR. _PEND._LUAR_BIASA/196912052 001121-

SETYO_WAHYU_WIBOWO/Ketuli anx.pdf 